\title{
Social Environment Utilization System Built on "Low-Cost Computing": Building Highly Versatile, Low-cost Remote Class Environment
}

\author{
Kazuya Murata *, Takayuki Fujimoto *
}

\begin{abstract}
Today, Online programs are now attracting a great deal of attention in the field of university education. The number of universities that offer online programs is increasing not only in Japan, but all around the world. Education through online classes is now common, and it is becoming a worldwide phenomenon. Currently, there are two major methods of remote education in Japan: "Two-way simultaneous method" and "On-demand method." "Two-way simultaneous method" enables students in another location to attend the class real time, using dedicated hardware supported by satellite communication or the Internet. "On-demand method" is a way by which the content of a recorded class is distributed on the Internet. Students can attend the class by viewing it. However, Two-way simultaneous method is the common way currently employed by most Japanese universities when they deliver remote classes. This is because stable communication needs to be ensured. However, construction of a remote class environment is a very expensive system. As described above, most Japanese universities have built remote class environment to deliver remote classes, using expensive dedicated hardware. However, with the remarkable development of computers and communication environments in recent years, anyone can now enjoy high-speed communication environment like 5G. Thus, we aim to build, in this research, an environment for simultaneous and bidirectional remote classes without using the dedicated remote class hardware. We aim to achieve this, minimizing the cost by using free or low-cost software. In this study, we define the above idea and method as "Low-Cost Computing." In this research, we define "Low-Cost Computing" as combining several common items to create, at a very low cost, something that offers high performance that would have taken a high cost to deliver. Based on this concept of "Low-Cost Computing", we construct in this research a low-cost remote class environment that anyone can easily use.
\end{abstract}

Keywords: Remote Class, Remote Class Environment, Low-Cost Computing,

\section{Introduction}

Online programs are now attracting a great deal of attention in the field of university education. The number of universities that offer online programs is increasing not only in Japan, but all around the world. Education through online classes is now common, and it is becoming a

* Graduate School of Information Sciences and Arts, Toyo University, Saitama, Japan 
worldwide phenomenon. Online university courses are widely offered particularly in the United States. In the United States, online university classes utilize a wide variety of media such as books, printed materials, audio media including CDs and radio, and Internet conference systems. In recent years, Internet has become the most common method of delivering classes. The biggest difference between Japanese and American online university programs is the accreditation method to ensure quality of education. In Japan, starting a correspondence-based educational institution requires accreditation by the Ministry of Education, Culture, Sports, Science and Technology. The Ministry maintains the high quality of Japanese education by raising the bar. On the other hand, there is no government agency in the United States that accredits educational institutions. There are private accrediting agencies in the United States that ensures schools meet certain educational standards. In the United States, the quality of education is maintained through this system of accreditation. The system makes it possible for students to receive the same quality of education in online programs as in regular programs. In this way, degrees in various disciplines can be earned through online university programs in the United States. It would be extremely difficult to have degrees from unaccredited institutions accepted in the society. Overall, online university programs are quite advanced and widely available in the United States.

In Japan, on the other hand, online education programs have been developing at a much slower pace. In Japan, on the other hand, online education programs have been developing at a much slower pace. For this reason, these lesser-known programs/universities might be generally perceived as "not credible". While it is basically possible to earn degrees through online programs, only limited number of institutions provide ways to earn master's or higher degrees. Online programs are not even available with institutions considered to be top universities, and middle-ranking universities such as Toyo University do not offer any degrees. Therefore, it can be said that the current online education in Japan is playing a "complementary" role. However, as network and computer technologies have been developed dramatically in recent years, Japanese universities have been actively working to offer degrees through online programs just like their American counterparts. In fact, Toyo University has begun running a pilot program of online education, and plans are underway to establish a department of online education in the future. In addition to Toyo University, pilot programs of online university education have been implemented across Japan in recent years. It is now attracting much attention as a way of delivering education. Under current Japanese law, if you were attending a regular program of a university, up to 60 out of 124 credits required for graduation can be earned through online courses, which is the upper limit on online course credits. With online universities, you can earn all 124 credits required for graduation through online courses.

Currently, there are two major methods of remote education in Japan: "Two-way simultaneous method" and "On-demand method". "Two-way simultaneous method" enables students in another location to attend the class real time, using dedicated hardware supported by satellite communication or the Internet. The method is literally simultaneous and bidirectional, and has a format closer to a face-to-face class. An advantage of this method is that it is possible to deliver a remote class anywhere that functions as a classroom. On the other hand, there are some constraints such as environment, method of teacher-student communication and Q\&A time. For example, the class needs to take place in an environment similar to a face-to-face class, and teacher and students need to communicate with each other via video and audio. Time for students to ask questions also need to be secured. "On-demand method" is a way by which the content of a recorded class is distributed on the Internet. Students can attend the class by viewing it. An advantage of this method is that it does not require a facility meant to be used as a classroom since the online class is delivered using a video viewing platform such as YouTube. With On-demand method, most students attend classes, using a personal computer, and it is no 
exaggeration to say that most of them do so from home. From its ease of use, the method is in high demand in Japan among working adults who cannot physically take university classes as well as international students. On-demand method has some disadvantages as well. In this method, the recorded class content is basically distributed unilaterally. Therefore, it is very difficult for the student viewers to immediately ask questions and have discussions. If on-demand classes are to be delivered on campus-based universities, it would be very difficult to secure enough time for Q\&A and discussions. This poses a question about guaranteeing sufficient education. Due to these challenges, On-demand method is currently employed in Japan only by distance learning universities. For these reasons, Two-way simultaneous method is the common way currently employed by most Japanese universities when they deliver remote classes. This is because stable communication needs to be ensured. In Two-way simultaneous online class, a real-time connection is established between two locations, where video/audio signals are continuously transmitted and received. Therefore, without a robust communication environment, the connection would become unstable, threatening the delivery of the class. Due to this problem, most universities giving remote classes use remote class/teleconference hardware products from providers. In fact, Toyo University uses a remote conferencing system called "PCS-XG80" provided by Sony Corporation to deliver remote classes by connecting three campuses. However, constructing this remote class system costs as much as over 10 million yen.

As described above, most Japanese universities have built remote class environment to deliver remote classes, using expensive dedicated hardware. However, with the remarkable development of computers and communication environments in recent years, anyone can now enjoy high-speed communication environment like $5 \mathrm{G}$. Building a stable communication environment for teleconference or remote classes is now possible by using a personal computer and free software. Thus we aim to build, in this research, an environment for simultaneous and bidirectional remote classes without using the dedicated remote class hardware. We aim to achieve this, minimizing the cost by using free or low-cost software. In this remote class environment, basic equipment is required. We use free software for system construction. Therefore, we aim to build a system that can be built by anyone for a very low cost. In this study, we define the above idea and method as "Low-Cost Computing." In the next chapter, we describe a new method this research proposes: "Low-Cost Computing".

\section{About "Low-Cost Computing"}

In this research, we propose a method of constructing a system or environment that has functions equivalent to expensive systems and services by combining common software and equipment available for low or no cost. We define this technique as "Low-Cost Computing" in this research. "Low-Cost Computing" is a technique that combines common, inexpensive equipment, software, and services to achieve the level of performance expensive commercial equipment or dedicated equipment offers. Not only can the technique achieve cost reduction, but it also enables anyone to easily operate, solve problems or make corrections since only common products are used. Therefore, it brings benefits in terms of maintenance and running costs as well as development and utilization.

One example of "Low-Cost Computing" is virtual currency. Virtual currency is an electronic currency exchanged as electronic data only on the Internet without their values guaranteed by national governments. There are various types of virtual currencies, and they often use "distributed network" as an underlying technology. In a distributed network, data is managed using users' computers rather than a server for data management. This technology is one through 
which all users manage data by communicating one another via a P2P network. In other words, virtual currency is made possible by combining computers of all users and the network to manage data. It can be described as network-based "Low-Cost Computing". Another example is supercomputer. Supercomputers are expected to deliver extremely high performance, and therefore require extremely high costs for development, operation, and maintenance. However, in theory, if a countless number of common computers could be connected in parallel, they should rival or even exceed a supercomputer in performance. If all the computers of the world could be connected as parallel computers, it would be possible to construct with "Low-Cost Computing" a system that can surpass any supercomputers with its world's highest performance. Also, a well-known example is building a bipedal walking robot out of a plastic model kit, a creation of Tomotaka Takahashi, President and CEO of ROBO GARAGE Co., Ltd. In the 2000s, companies around the world were competing to create high-performance "biped walking robots", and a huge investment was made into these efforts. Meanwhile, Tomotaka Takahashi was also committed to the research of bipedal walking robots at the Faculty of Engineering, Kyoto University. Then, they independently developed an electromagnetic absorption biped walking robot by modifying a commercially-available plastic model. He later obtained a patent, developed and launched sales of his original bipedal walking robot "Gunwalker" from a radiocontrolled model manufacturer, and has sold 5,000 units worldwide. In this case, while other companies were making a huge investment in the development of bipedal robots, he completed a unique bipedal walking robot at a very low cost by combining a commercially-available plastic model and electromagnets. We consider this example as fundamentally the same as the idea of "Low-Cost Computing."

In this research, we define "Low-Cost Computing" as combining several common items to create, at a very low cost, something that offers high performance that would have taken a high cost to deliver. Based on this concept of "Low-Cost Computing", we construct in this research a low-cost remote class environment that anyone can easily use.

\section{Summary of Remote Class Environment using "Low-Cost Computing"}

In this research, an environment that enables low-cost remote classes was constructed based on the concept of "low-cost computing", using only general equipment, systems, and services, regarding the field of "the education through remote classes." We conducted several trials to build a remote class environment. This chapter describes an example for construction and operation.

\subsection{Construction Example}

A remote class environment was constructed by combining general equipment and systems. We have worked on various test for years, and the following is the currently used equipment. 
Table 1: Equipment list

\begin{tabular}{|l|l|}
\hline No.1 & Laptop (we are using MacBook in this research) \\
\hline No.2 & Free Video Chat Software (In this case Google Hangouts) \\
\hline No.3 & Network Environment in Toyo University \\
\hline No.4 & Projector (with VGA or HDMI connectors) \\
\hline No.5 & Microphone \\
\hline No.6 & Sound Cables \\
\hline
\end{tabular}

As a matter of course, the above equipment is not always necessary. Any devices or systems having similar functions can be substituted for components of the proposed system. Therefore, there is an advantage that the system for a remote class can be constructed anywhere. With the proposed system, the remote classes were held successfully, and the classes were equivalent to the ones by using dedicated devices.

Next, we will outline the implementation of remote classes in this research. In the remote class environment constructed in this research, we basically assume that two computers will be used in one place. The first computer is for a class facilitation. Using this computer, a teacher can share class materials and project the computer screen on a big projector screen. In the classroom on the delivery side, the class materials created by the teacher are projected onto the screen, and at the same time, the class materials are shared with the computer in the classroom on the receiver side. Also, voice is transmitted/received from/with this main computer. The second computer is for "the classroom full view." It would not serve as a remote class only with the computer for class facilitation if the teacher could not grasp the situation in the classroom on the other side and that miscommunication may prevent students from proper understanding. By projecting the whole classroom view with the second computer, the easier environment for remote class facilitation is enabled.

\subsection{Operation Example}

A number of test operations have been carried out for this research to build a remote class environment based on "Low-Cost Computing." The test operation example is described in this section.

\subsubsection{The first trial operation "Synthetic Science"}

This operation was for a class using the remote class environment constructed in this research. For the class, "Synthetic Science" offered at Toyo university, the operation using the remote class environment was carried out. In the past, this remote class was delivered using a video conference system based on dedicated hardware. The dedicated hardware is used to connect several campuses of Toyo University via communication for the remote classes. Since this trial operation was still in the prototype stage, we conducted the remote class combining dedicated hardware and the remote class system proposed in this study. In the operation, we connected three campuses, Hakusan campus (Tokyo), Kawagoe campus (Saitama), and Asaka campus (Saitama).At the same time, we also added connection with Akita International University and the remote class had 4 bases in total. Figure 2 shows the trial operation. This figure shows the classroom in Kawagoe campus, and the video projected onto the projector screen is 
the classroom of Akita International University. In this way, by using the remote class environment constructed in this research, anyone can easily coordinate remote classes with other universities at low cost even between distant universities.

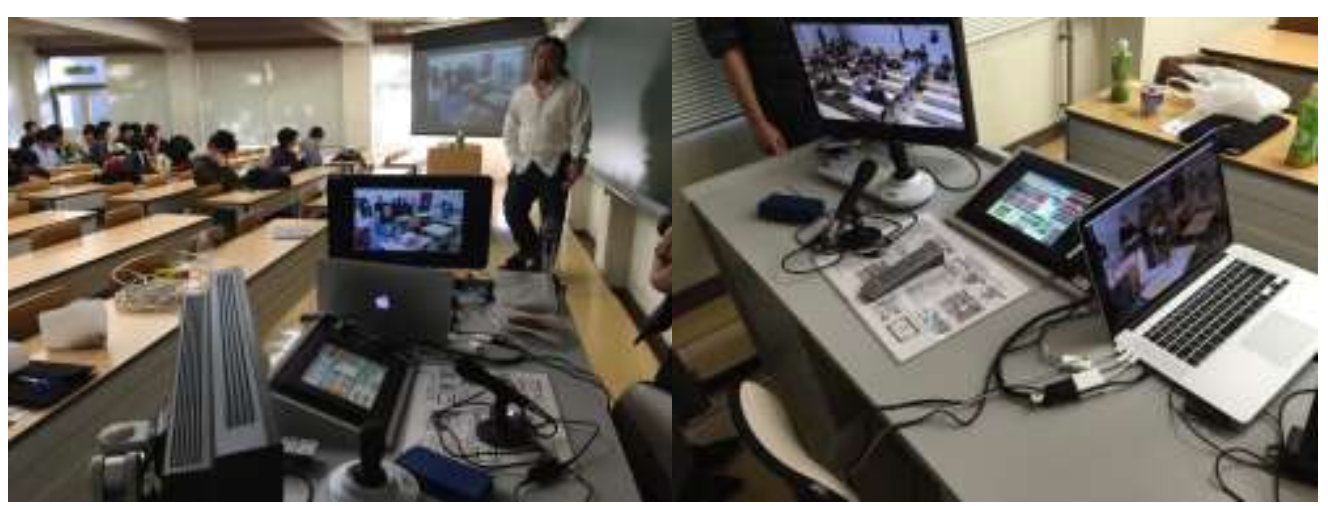

Figure 2: The First Trial Operation "Synthetic Science"

As a result of this trial operation, we could build the practical environment to some extent. However, there were some problems to be solved regarding video and sound. As for the video, there were some cases upon which the lengthy delays occurred by the network conditions of Toyo University besides constant subtle delay. With regards to the sound, feedback noises occurred several times.

\subsubsection{The second trial operation "Synthetic Science"}

This second trial operation was carried out with the improved remote class environment, based on the results of the first trial operation. As well as the first trial operation, we carried out a remote class using the environment built for this research at the class of "Synthetic Science" offered by Toyo University. However, unlike the first trial, we did not use the dedicated hardware for the remote class and conducted the class only with the remote class environment proposed in this research. In this trial operation, one assistant was assigned to each of three remote campuses of Toyo University, and the remote classes were conducted with Internet connection. Figure 3 shows the trial operation. This figure shows Kawagoe campus's classroom, and the video projected onto the projector screen is the classroom in one of other campuses. At the same time, a subject on a discussion was displayed and the system was open to the interactive discussion.

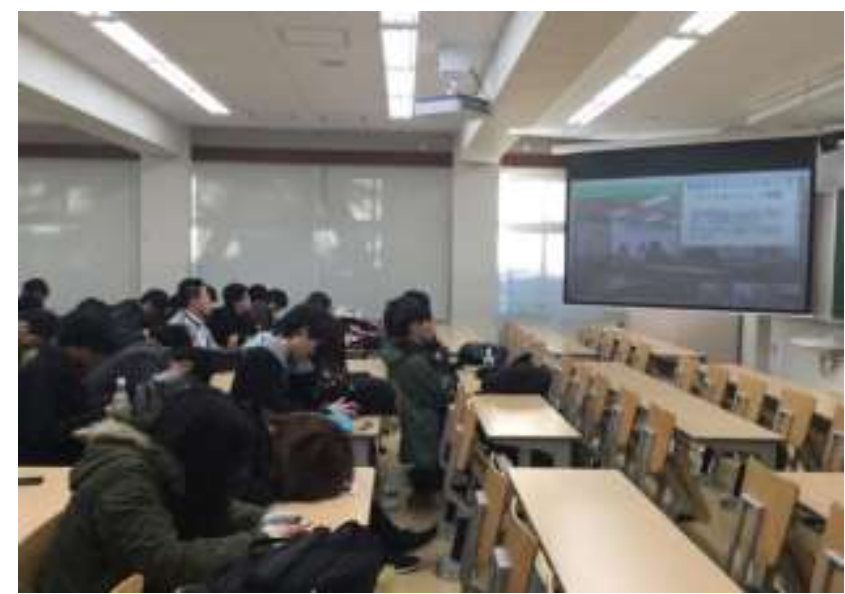

Figure 3: The Second Trial Operation "Synthetic Science" 
This trial was to solve the problem that occurred in the first trial operation. As a result, all the problems such as delay in video and sound, and feedback noises, have been cleared, and the remote class was carried out to the end without significant problems.

\subsubsection{The third trial operation "Mock Lecture"}

Based on the results of the second trial operation, we concluded that the basic form of the remote class environment based on Low-Cost Computing was almost completed. Therefore, the third trial operation was an example for utilization of this environment. In the third trial operation, a remote class with the proposed remote class environment was conducted for a mock lecture at Toyo University. Toyo University holds open campuses several times a year. As one of the related events, there is a "mock lecture" where you can experience a class in the actual format. In response to a request from the teacher in charge, we conducted a remote class using the remote class environment constructed for this research. This operation is a remote class connecting the Hakusan campus(Tokyo) and the Kawagoe campus(Saitama) in Toyo University. Figure 4 shows the classroom while the operation. Here was no problem with both video and sound, and the class was carried out successfully to the end. After the mock lecture, there was a question and answer session from a participant at Hakusan campus to the teacher at Kawagoe campus. The system resulted in the class's interactive atmosphere. From this, we assumed that the proposed system is effective from the viewpoint of interactivity.

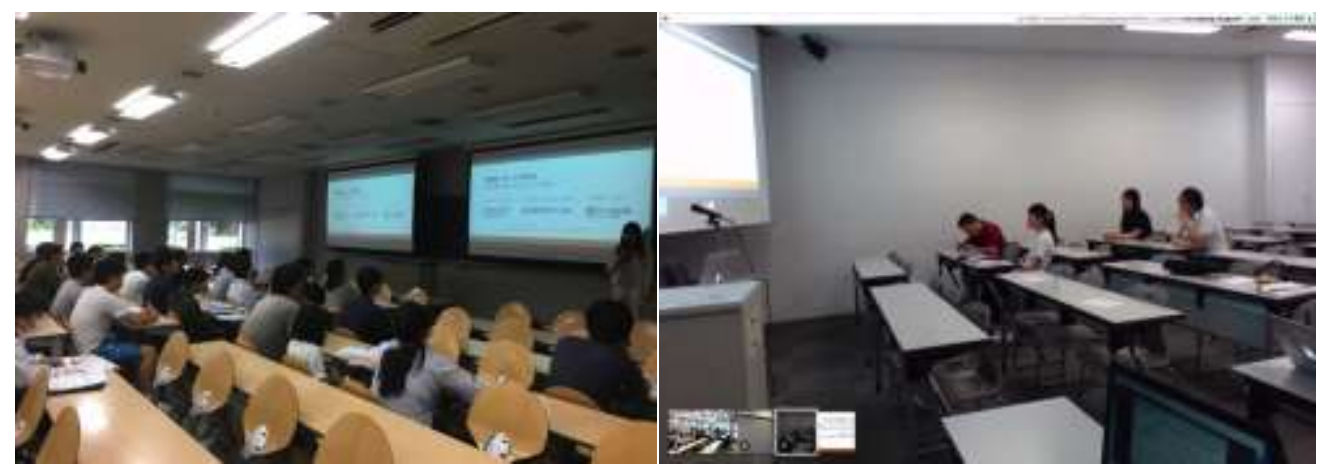

Figure 4: The Third Trial Operation "Mock Lecture"

By working on these trial operations, we concluded that we could build a remote class environment based on the concept of low-cost computing that can be called as almost the completed form.

\section{Current Remote Class Environment}

In this study, we have carried out several trial operations as described in the previous chapter. We have explored problems and points of improvement in the past trial operations, and we believe that the constructed system is now a low-cost remote class environment that can be generally called a completed form. This chapter describes the official operation using the completed remote class environment. 


\subsection{Full Operation of Remote Class Environment}

The conducted a remote class at Toyo University using the remote class environment constructed for this research. The remote class was carried out for "Sports and Nutrition", one of the classes offered by the Faculty of Food and Nutritional Sciences in Toyo University. "Sports and Nutrition" is a class for the qualification of a certified sports dietitian. This class is held at Toyo University's Itakura Campus in Itakura Town, Gunma Prefecture. Sports-related faculties that offer classes on sports are not only at the Itakura Campus but also at the Kawagoe Campus in Kawagoe City, Saitama Prefecture. However, "Sports and Nutrition" was offered only at the Itakura Campus. For this reason, the university and this research collaborated, and we created an environment where students on both campuses can take "Sports and Nutrition," connecting Itakura Campus and Kawagoe Campus by remote classes. The weekly remote class had 15 sessions from September 2018 to February 2019. Figure 5 outlines the remote class environment at that time. Figure 6 shows an example of computer construction on the delivery side in the operation.
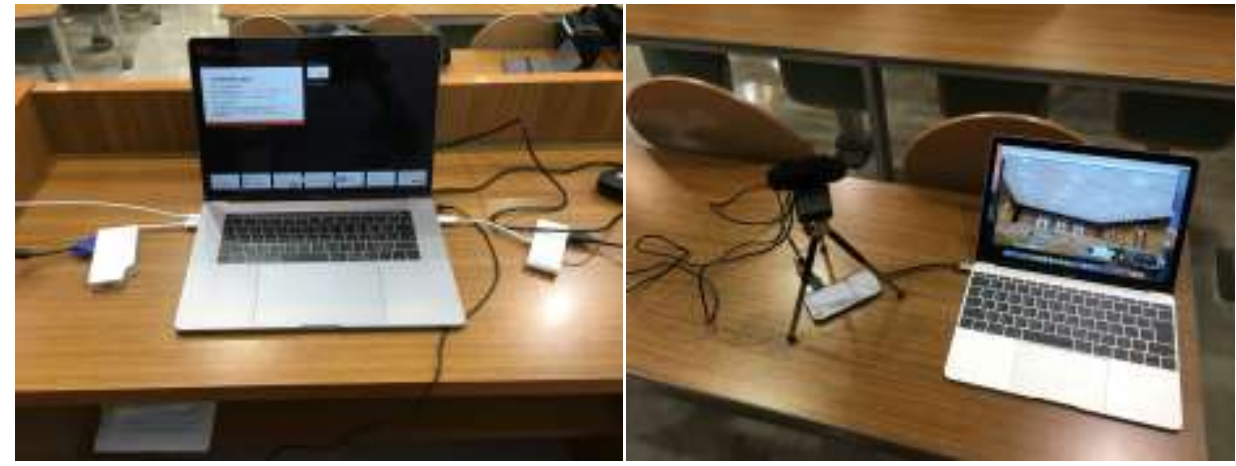

Figure 5: Construction example

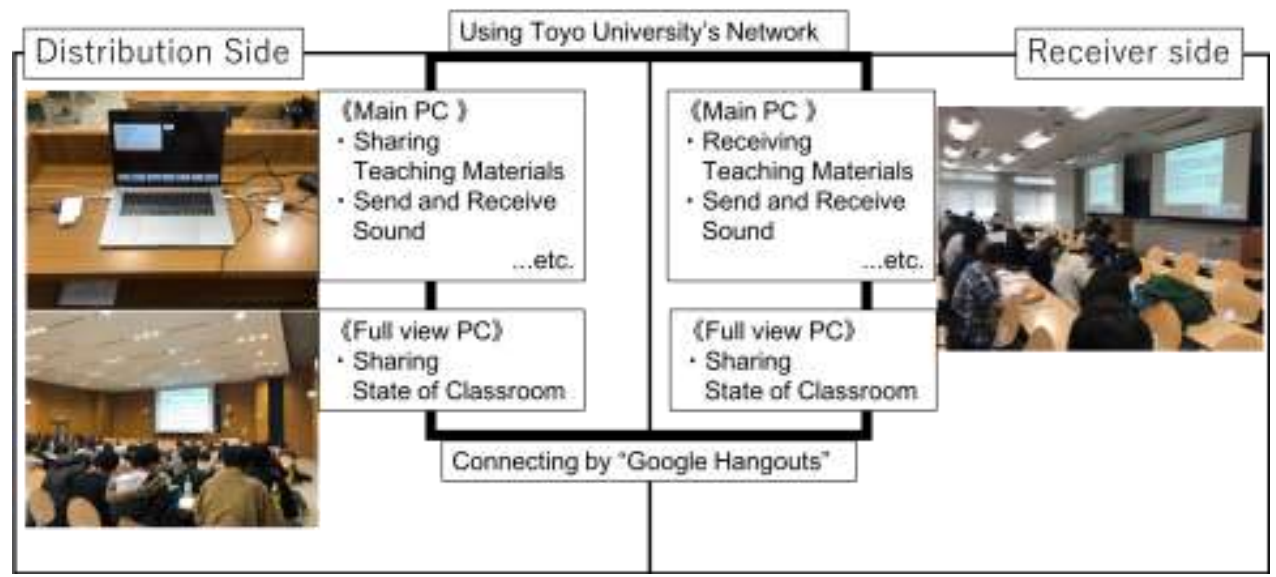

Figure 6: Summary diagram

We could deliver classes that was equivalent to the remote class using dedicated hardware without any major problems regarding all 15 lectures. However, there was only one sound issue: teacher's voice. In the early stage of this remote class, a "omnidirectionalctional" conference microphone was used as a voice input device. For that reason, we assumed that the teachers would not necessarily speak in front of the teacher's desk and they would move around to some extent. However, the "omnidirectional" microphones picked up all the ambient noises such as 
student chats and teachers' turning over pages of materials. As a result, it lowered the voice quality of teachers that is necessary for the class. To solve this problem, we introduced a new "unidirectional" condenser microphone. The quality of voice was dramatically improved now, and the sound problem was solved. In the present research, we plan to continue the use of the unidirectional microphones for future trial operations.

Regarding this remote class, a questionnaire survey was held in the last class to evaluate its usefulness. The next section demonstrates the results of the questionnaire survey.

\subsection{Questionnaire Survey of Remote Class by "Low-Cost Computing"}

We conducted a questionnaire in Toyo University's class as an operational example of remote class environment by "Low-Cost Computing." In this section, we summarize the survey results and study the evaluation from those results.

We conducted a questionnaire on the remote class delivered through Low-Cost Computing for 110 university students taking "Sports and Nutrition" at Toyo University. In each question, the remote class is rated using a 5-point rating scale. The questions used in this survey are shown below. And table 3 shows the attributes of the 110 students who rated the class.

Table 2: Questionnaire list

\begin{tabular}{|l|l|}
\hline Question 1 & How did you feel about this remote class? \\
\hline Question 2 & Was the "sound" of this remote class easy to hear? \\
\hline Question 3 & Was the "video" of this remote class easy to watch? \\
\hline Question 4 & $\begin{array}{l}\text { Was it easier to attend this remote class compared to regular, } \\
\text { face-to-face class? }\end{array}$ \\
\hline Question 5 & Were the classes delivered real time and running smoothly? \\
\hline Question6 & Would you like to attend a remote class again in the future? \\
\hline
\end{tabular}

Table 3: Subject attributes

\begin{tabular}{|l|l|}
\hline Sex & \multicolumn{1}{|l}{$3:$} \\
\hline Male & 92 \\
\hline Female & 18 \\
\hline
\end{tabular}

\begin{tabular}{|l|l|}
\hline Age & \\
\hline 18 & 17 people \\
\hline 19 & 75 people \\
\hline 20 & 13 people \\
\hline 21 & 4 people \\
\hline 23 & 1 people \\
\hline
\end{tabular}

First, Table 4 shows the responses to Question 1: How did you feel about this remote class?

Table 4: Result of Question 1

\begin{tabular}{|c|c|c|c|c|}
\hline \multicolumn{5}{|c|}{ Q1. "How did you feel about this remote class?" } \\
\hline Very bad & Bad & Neither & Good & Very good \\
\hline $\begin{array}{c}6 \\
(5.5 \%)\end{array}$ & $\begin{array}{c}20 \\
(18.2 \%)\end{array}$ & $\begin{array}{c}57 \\
(51.8 \%)\end{array}$ & $\begin{array}{c}23 \\
(20.9 \%)\end{array}$ & $\begin{array}{c}4 \\
(3.6 \%)\end{array}$ \\
\hline
\end{tabular}


For this remote class, the total number of students who answered "very good" / "good "and the total number of those who answered "very bad"/ "bad" were almost the same. It is likely to be the result of respondents' consideration to various operational issues such as network issue at the University and sound issues. The remote class environment constructed in this research still has some parts that need to be improved through trial and error, and we plan to solve various problems in our future research.

Next, Table 5 shows the responses to Question 2: Was the "sound" of this remote class easy to hear?

Table 5: Result of Question 2

\begin{tabular}{|c|c|c|c|c|}
\hline \multicolumn{4}{|c|}{ Q2. "Was the "sound" of this remote class easy to hear?" } \\
\hline Very bad & Bad & Neither & Good & Very good \\
\hline 7 & 55 & 27 & 18 & 3 \\
$(6.4 \%)$ & $(50 \%)$ & $(24.5 \%)$ & $(16.4 \%)$ & $(2.7 \%)$ \\
\hline
\end{tabular}

The majority of the students answered "very bad" or "bad", which shows that it was generally difficult to hear the sound. As a cause of this negative rating, in the remote class environment built in Sports and Nutrition this time, we used the "omnidirectional" conference microphone as a sound input device in the first half of all 15 classes. In the second half of the class, we introduced a "unidirectional" microphone, and some students commented that the sound quality had been improved dramatically. It is thought that the students who were concerned about the use of "omnidirectional" microphone in class answered "very bad" or "bad" in the questionnaire. Students who answered "very good", "good" or "neither" are considered to have responded based on their experience of the class using "unidirectional" microphone. In consideration of this survey result, we are planning in this research to build a remote class environment using "unidirectional" microphone for future operation.

Next, Table 6 shows the responses to Question 3: Was the "video" of this remote class easy to watch?

Table 6: Result of Question 3

\begin{tabular}{|c|c|c|c|c|}
\hline \multicolumn{4}{|c|}{ Q3. "Was the "video" of this remote class easy to watch?" } \\
\hline Very bad & Bad & Neither & Good & Very good \\
\hline $\begin{array}{c}1 \\
(0.9 \%)\end{array}$ & $\begin{array}{c}13 \\
(11.8 \%)\end{array}$ & $\begin{array}{c}48 \\
(43.6 \%)\end{array}$ & $\begin{array}{c}37 \\
(33.6 \%)\end{array}$ & $\begin{array}{c}11 \\
(10 \%)\end{array}$ \\
\hline
\end{tabular}

Approximately half of the students answered either "very good" or "good" regarding the visibility of the "video". The video quality can be influenced by the network environment, and some students answered "bad" due to the rare issues which caused the video quality to deteriorate. However, in this remote class, the teaching materials such as PowerPoint presentations were mainly shared and distributed as video. It basically took the form of projection of characters and images, and the video quality was not so bad as to affect readability of the characters. Therefore, we find no problem in the current format for visibility of the video.

Next, Table 7 shows the responses to Question 4: Was it easier to attend this remote class compared to regular, face-to-face class? 
Table 7: Result of Question 4

\begin{tabular}{|c|c|c|c|c|}
\hline \multicolumn{5}{|c|}{ Q4. "Was it easier to attend this remote class compared to } \\
regular, face-to-face class?" \\
\hline Very bad & Bad & Neither & Good & Very good \\
\hline 5 & 37 & 49 & 13 & 6 \\
$(4.5 \%)$ & $(33.6 \%)$ & $(44.5 \%)$ & $(11.8 \%)$ & $(5.5 \%)$ \\
\hline
\end{tabular}

When compared with regular, face-to-face classes offered at Japanese universities, many students answered "very bad" or "bad". As described for Question 2, there was an issue with the sound quality, which is considered to have resulted in these responses. In addition, when compared with face-to-face classes, the sound quality may possibly be influenced by the teacher's "voice", too. Now that the voice issue has been solved, we are planning to improve the remote class environment in order to make it easier for the students to engage in the class sessions. Also, we think the answer "neither" is very important. For this question, the result reflects the "comparison with regular classes". In other words, it is "hard to determine which was good when compared with regular classes." We believe it means that we have been successful in constructing a remote class that is as good as regular class.

Next, Table 8 shows the responses to Question 5: Were the classes delivered real time and running smoothly?

Table 8: Result of Question 5

\begin{tabular}{|c|c|c|c|c|}
\hline \multicolumn{5}{|c|}{ Q5. "Were the classes delivered real time and running } \\
smoothly?" \\
\hline Very bad & Bad & Neither & Good & Very good \\
\hline $\begin{array}{c}1 \\
(0.9 \%)\end{array}$ & $\begin{array}{c}14 \\
(12.7 \%)\end{array}$ & $\begin{array}{c}55 \\
(50 \%)\end{array}$ & $\begin{array}{c}33 \\
(30 \%)\end{array}$ & $\begin{array}{c}7 \\
(6.4 \%)\end{array}$ \\
\hline
\end{tabular}

Regarding this operation, a relatively large number of students answered "very good" or "good" to this question. Therefore, we believe the remote class was running smoothly without any major issues. However, there was a problem that affected the classroom procedure. It is the problem with Toyo University's network. The remote class environment for this operation was constructed using Toyo University's network. The network is designed to be connected by any students of the University. Therefore, when the network has a huge number of connections, the load increases, which leads to delays. In the actual remote class operation, too, the problem was encountered several times when delays occurred due to the large number of connections. Nevertheless, after trial and error in the connection method for the latter half of all these sessions, the classes were held successfully, and a smooth class environment has been constructed as a result. The ratings in this question seem to reflect this problem.

Finally, Table 9 shows the responses to Question 6: Would you like to attend a remote class again in the future? 
Table 9: Result of Question 6

\begin{tabular}{|c|c|c|c|c|}
\hline \multicolumn{5}{|c|}{ Q6. "Would you like to attend a remote class again in the } \\
future?" \\
\hline Very bad & Bad & Neither & Good & Very good \\
\hline $\begin{array}{c}6 \\
(5.5 \%)\end{array}$ & $\begin{array}{c}21 \\
(19.1 \%)\end{array}$ & $\begin{array}{c}56 \\
(50.9 \%)\end{array}$ & $\begin{array}{c}20 \\
(18.2 \%)\end{array}$ & $\begin{array}{c}7 \\
(6.4 \%)\end{array}$ \\
\hline
\end{tabular}

In this question, we received as many positive ratings as negative ones. Overall, there was no problem in terms of the class procedure. On the other hand, it is considered that we received the above ratings this time due to the issues including the delays in sound and video. However, now the factors such as sound and video have been improved, and we hope next year's operation will get a higher evaluation.

\section{Conclusion and Future Work}

In this research, a new remote class environment that can be operated at low cost was constructed as one of a research projects upon the theme of social environment utilization system by "Low-Cost Computing." At present, we believe that a remote class environment that can be called as almost completed form, has been built. As a whole, though there still remain some problems and rooms for improvement in the "Low-Cost Computing" remote class environment, we believe that it was operated as successfully as the existing remote class. In addition, we think that the issues in this operation were mostly caused by "human errors". For example, in the case of sound issues, we initially thought that omni directional microphone was good enough. After the operation started, however, we realized we had not considered microphone sensitivity/performance or the volume of teacher's voice, and the audience ended up experiencing difficulty hearing. With these in mind, we would like to continue with trials as well as official operations in this research. Ultimately, we plan to create a "manual". We have built a remote class environment using Google Hangouts. However, there are various types of video chat software packages that can be used for remote classes. By creating a "manual" to build a remote class environment using all these video chat software packages, we will establish the system upon which anyone can easily build a remote class environment that can utilize various environments. We are also considering the introduction of a "class support application" as a future development. At present, it is difficult to gather feedback or opinions from students without teacher's deep understanding of the skill to collect them. Therefore, we are considering the introduction of a class support application to help teachers to facilitate classes. In this way, we aim to build a more functional remote class environment. 


\section{References}

[1] M. KUDO, "Study by Distance Lectures Given Using Information and Communication Technology in an Art Class of Junior High School in an Isolated Island in Hokkaido", The Journal for the Association of Art Education (39), pp.113-125, 2018-03

[2] M. ITO, H. ICHIMURA, S. MUNKH-OCHIR, “3E05 A Case Study of Distance-Learning System for Physics Class between Salesian Polytechnic and Mongol Kosen by Using The NTT Smart Video Conference Service", Proceedings of Annual Conference of Japanese Society for Engineering Education 2018(0), pp/454-455, 2018

[3] N. NAKANO, "Experiences of the Interactive Classes Using the Free Software "Web Clivker", Journal of faculty and staff development in higher education (15), pp.121-126, 2017-03

[4] S. AIZAWA, Y. KOBAYASHI, "A study of remedial education on the utilization of a remote education system for junior high school refusal students" Studies in Educational Research and Traning, Center for Educational Research and Traning, Gifu SHotoku Gakuen University, (17), pp.243-250, 2017

[5] T. KOIDE, H. YAMADA, S. KOBAYASHI, "Practical approaches to interactive lectures for progress of enginnering design class", Research reports of Tokyo Metropolitan College of Industrial Tevhnology (10), pp.82-88, 2016-03

[6] K. NAKANO, "An attempt of Interactive Classes using free software "PingPong"”, Bulletin of the Faculty of Education Ehime University (62), pp.135-142, 2015-10

[7] F. IZUMI, S. OKABE, "Education Environments for Interactive Distance Learning”, Journal of Higher Education and Lifelong Learning (22), pp.75-81, 2015-03

[8] M. KAMATA, "Problems and View of e-Learning Systems to Support Interactive Learning in Large Classes", The Journal of Chiba University of Commerce 52(1), pp.87-101, 2014-09

[9] K. MURATA, T. FUJIMOTO, "Construction of Remote Class Environment that Enables Interactive Communication Especially for Active Leaning" $7^{\text {th }}$ International Conference on innovative practices in Business, Social Sciences and Humanities Research, Dubai UAE, 2017-12

[10] K. MURATA, K. FUJITA, T. FUJIMOTO, "Construction of Remote Class System that Enables Interactive Communication and Comparison Existing Remote Class System", The 17th International Conference on E-Learning, e-Business, Enterpritse Info Systems, \& e-Government (EEE'18), Nevada, USA, 2018-08 